\title{
Assessment of Psychological Burden and Occupational Burnout in Nurses Working in Intensive Care Units in Poland, Slovakia and the Czech Republic
}

\section{G. Debska (Grazyna Debska)', H. Kaducakova (Helena Kaducakova),2, A. Kratka (Anna Kratka) ${ }^{3}$, M. Pasek (Malgorzata Pasek)}

${ }^{1}$ Andrzej Frycz Modrzewski Krakow University - Faculty of Medicine and Health Sciences, Poland

${ }^{2}$ Catholic University in Ruzomberok - Faculty of Health, Slovakia

3 Tomas Bata University in Zlín - Faculty of Humanities, Czech Republic

\section{E-mail address:}

helena.kaducakova@ku.sk

\section{Reprint address:}

Helena Kaducakova

Faculty of Health

KU in Ruzomberok

Namestie A.Hlinku 48

03401 Ruzomberok

Slovakia

Source: Clinical Social Work and Health Intervention

\section{Reviewers:}

Marian Karvaj

St. Elisabeth University of Health and Social Work, Bratislava, Slovakia

Gunther Dorfmeister

Vienna General Hospital, Vienna, Austria

\section{Key words:}

Professional Burden. Nurse. Intensive care.

\section{Publisher:}

International Society of Applied Preventive Medicine i-gap

CSWHI 2019; 10(2): 53 - 61; D0I 10.22359/cswhi_10_2_08 @ 2019 Clinical Social Work and Health Intervention 


\section{Abstract:}

The work of an intensive care nurse involves the direct care of patients with life-threatening conditions. In this situation, the prevention of burdens associated with this work becomes important, but it must be preceded by their diagnosis. This diagnosis is possible using standardized tools for the subjective assessment of a psychological burden and an occupational burnout. Therefore, the aim of our research was to determine whether nurses working in the same specialties in different countries are exposed to the same burdens.

The study involved 312 nurses, divided into three groups depending on their country of origin and in which they worked. Two equal groups of nurses each contained 106 people from Slovakia and the Czech Republic, while the third group was comprised of 100 people from Poland. The age of the groups studied, taken together was $(\mathrm{M}=35.53 \pm 8.86$ min. 22 years max. 60 years).

Various results were observed as regards psychological burden and occupational burnout in the groups studied. The strongest differences related to overload, non-specific reaction to stress, feelings of personal achievement and depersonalization, which depended on age and length of service in each workplace. Assessment of the mental load can be used to improve the organization of Nurses' work creating safe working conditions in studied countries, taking into consideration the mobility of the workforce in the European Union.

The study was financed with funds from the Ministry of Science and Higher Education for Scientific and Development Research within its status activity (reference number of the research task: WZiNM/ DS/7/2015-KON).

\section{Introduction}

The work of intensive care nurses involves great pressure resulting from the direct care of patients with life-threatening conditions. It is very important that nurses in this specialty, in addition to having knowledge of procedures and their proper implementation, are also able to respond adequately to sudden and unpredictable situations, as well as cooperate with the therapeutic team. This pressure is also a result of the environment and working conditions. Consequently, this situation may cause occupational burnout and mental load as well as a decrease in life satisfaction (1). It seems, therefore, that the elements that determine the particular attractiveness of this nursing specialty can be a source of psychological and physical burden. In order to reduce the workload and the risk of occupational burnout syndrome, it is necessary to understand the causes, types and frequency of adverse and stressful factors $(1,2)$. In this situation, it is important to prevent these burdens after having first recognized them. This is possible thanks to the use of standardized tools for subjective psychological burden assessment. One of these is the Meister Questionnaire, used in the Czech Republic and Slovakia and recently also validated in Poland $(3,4,5,6)$. When conducting comparative research on the phenomenon of mental burden in the work of nurses, international 
research is important as it allows the phenomenon in different countries to be compared. Therefore, the aim of our research was to check whether nurses working in the same specialties in different countries are exposed to the same mental load. A group of nurses working in intensive care units in Poland, Slovakia and in the Czech Republic was used for comparison purposes based on the assumption that the populations of these countries are similar in demographic terms and in the socio-cultural and organizational conditions of the work environment. The aim of the study was to assess the level of psychological burden and burnout in nurses working in Intensive Care Units in Poland, Slovakia and the Czech Republic.

\section{Methods}

The study involved 312 nurses (100\% women), who were divided into three groups depending on their country of origin and in which they worked. Two equal groups of nurses from Slovakia and the Czech Republic each contained 106 people, while the third group from Poland had 100 people. The age of the group studied, taken together was $(\mathrm{M}=35.53 \pm 8.86$ with a minimum of 22 years and a maximum of 60 years). At that time, the group being studied had been working in Intensive Care Units on average for $10.13 \pm 9.01$ years. Their length of service in their current workplace varied from 0.5 to 40 years.

In the study, a diagnostic survey was carried out using two standardized tools. One of these was a Meister Questionnaire, which is used for the subjective assessment of the psychological burden associated with a profession. It consists of 10 questions, divided into three subscales: overload, monotony and non-specific load (understood as a non-specific reaction to stress). The first subscale, overload, relates to: time pressure, great responsibility, problems and conflicts. The second (monotony) differentiates: a low level of satisfaction, tedious work and monotony. The third subscale (the non-specific factor) includes such characteristics as: nervousness, over-saturation, fatigue and reduced performance. With the group of Polish nurses, a Polish version of the Meister Questionnaire, adapted by G. Dębska et al (6), was used. With the Slovak group, the version that appears in the Regulations of the Ministry of Health of the Slovak Republic (3) was used, and with the Czech nurses, the version published by A. Hladky (5) and used in the research of Z. Židková (4). All three language versions achieve an acceptable level of psychometric criterion validity in terms of reliability and accuracy (Cronbach $\alpha$ above 0.77) (6). The second tool used in the study was the MBI Occupational Burnout Questionnaire (Maslach Burnout Inventory), which consists of 22 statements assessing the frequency of certain feelings in the participants on a scale from 0 to 6 . Each statement is assigned to one of three separate subscales: emotional exhaustion, depersonalization, feelings of personal achievement (7).

To answer the research questions, statistical analyses were carried out using the IBM SPSS Package, Statistics 23. It was used to analyze the basic descriptive statistics and to analyze the correlations using Pearson's $r$ coefficient, as well as to perform monofactorial analysis of variance and the Kruskal-Wallis Test. Games-Howell Post Hoc Tests were used as well as NIR. The Kolmogorov-Smirnov Test with the Lilliefors correction was used to Test for the normality of the distribution of the measured quantitative variables. The level of significance was considered to be $p<0.05$.

\section{Results}

The groups studied differ in their age range $-F(2,309)=9.73 ; p<0.001$, because the Polish group is statistically significantly 
older $(M=38.43$; $S D=9.41)$ than the participants from both Slovakia $(\mathrm{M}=35.15$; $\mathrm{SD}=9.27)$, and the Czech Republic $(M=$ 33.17; $S D=7.03$ ) (Table 1). participants' age with their sense of personal achievement $(r=-0.183, p=0.058)$ and depersonalization $(r=-0.1778, p=0.05)$. Both correlations are weak and negative.

Table 1: Age of the participants

\begin{tabular}{|l|c|c|c|c|c|c|}
\hline Age & $\mathrm{N}$ & $\mathrm{M}$ & $\mathrm{Me}$ & $\mathrm{SD}$ & Min. & Max. \\
\hline Poland & 100.00 & 38.43 & 39,00 & 9.41 & 22.00 & 60.00 \\
\hline Slovakia & 106.00 & 35.15 & 34.00 & 9.27 & 22.00 & 60.00 \\
\hline Czech Republic & 106.00 & 33.17 & 32.00 & 7.03 & 22.00 & 56.00 \\
\hline Whole group & 312.00 & 35.53 & 35.00 & 8.86 & 22.00 & 60.00 \\
\hline
\end{tabular}

M - mean; Me-median; SD - standard deviation

The relationships of age with occupational burnout and mental strain in the groups studied, are presented in Table 2. There is a significant correlation, at the level of statistical trend, of the Polish
However, the age of the participants from Slovakia correlates significantly, at the level of statistical trend, only with monotony $(r=0.172, p=0.058)$. This correlation is weak and positive.

Table 2: Correlations of age with occupational burnout and mental load in the groups studied

\begin{tabular}{lllll}
\hline & & age Poland & age Slovakia & age Czech Republic \\
\hline \multirow{2}{*}{ overload } & Pearson's r & 0.024 & -0.111 & 0.002 \\
monotony & Significance & 0.814 & 0.258 & 0.983 \\
& Pearson's r & 0.140 & $\mathbf{0 . 1 7 2}$ & -0.023 \\
non-specific factor & Significance & 0.165 & $\mathbf{0 . 0 5 8}$ & 0.812 \\
& Pearson's r & 0.034 & -0.034 & -0.039 \\
overall mental load & Significance & 0.736 & 0.726 & 0.695 \\
\multirow{2}{*}{ emotional exhaustion } & Pearson's r & 0.072 & -0.115 & -0.028 \\
\multirow{2}{*}{ sense of personal } & Significance & 0.479 & 0.239 & 0.778 \\
achievement & Pearson's r & 0.040 & 0.080 & 0.103 \\
depersonalization & Significance & 0.695 & 0.417 & 0.292 \\
\multirow{2}{*}{$\begin{array}{l}\text { overall occupational } \\
\text { burnout }\end{array}$} & Pearson's r & $\mathbf{- 0 . 1 8 3}$ & 0.016 & 0.123 \\
\hline
\end{tabular}


Next, the relationship between length of service in the current workplace and burnout and psychological burden was checked. For the Polish nurses, length of service in the current workplace only correlates with monotony $(r=0.212, p=0.034)$. It is a weak positive correlation. However, in the Czech group, length of service in the current workplace correlates with depersonalization and overall burnout $(r=0.228, p=0.019, r=$ $0.212, p=0.030$, respectively). Both are weak, positive correlations. The other scales are not significantly related. On the other hand, no such relationship was observed for the Slovakian group (Table 3). for independent samples was carried out for this purpose. The results show that there are statistically significant differences between nurses from Poland, Slovakia and the Czech Republic as regards general psychological burden and occupational burnout. The differences relate to the following subscales: overload, non-specific factor, sense of personal achievement and depersonalization. It turns out that for the overload subscale, the group from the Czech Republic differs from the other two groups, while the remaining groups do not differ from each other. Nurses from the Czech Republic achieved a significantly lower score on these scales compared

Table 3: Correlations between length of service in the current workplace and occupational burnout and mental load

\begin{tabular}{lllll}
\hline \multirow{2}{*}{ overload } & & Poland & Slovakia & Czech Republic \\
\hline \multirow{2}{*}{ monotony } & Pearson's r & -0.054 & -0.061 & 0.107 \\
& Significance & 0.591 & 0.537 & 0.277 \\
non-specific factor & Pearson's r & 0.212 & -0.008 & -0.005 \\
& Significance & 0.034 & 0.932 & 0.957 \\
overall load & Pearson's r & 0.142 & -0.002 & -0.012 \\
\multirow{2}{*}{ emotional exhaustion } & Significance & 0.158 & 0.981 & 0.907 \\
\multirow{2}{*}{ sense of personal achievement } & Pearson's r & 0.129 & -0.028 & 0.028 \\
& Significance & 0.200 & 0.774 & 0.774 \\
depersonalization & Pearson's r & 0.035 & 0.105 & 0.158 \\
& Significance & 0.732 & 0.283 & 0.108 \\
& Pearson's r & -0.106 & -0.017 & 0.108 \\
\cline { 2 - 3 } overall occupational burnout & Significance & 0.296 & 0.861 & 0.272 \\
& Pearson's r & -0.071 & -0.023 & 0.228 \\
& Significance & 0.484 & 0.817 & 0.019 \\
& Pearson's r & 0.047 & 0.048 & 0.212 \\
& Significance & 0.641 & 0.623 & 0.030 \\
\hline
\end{tabular}

The differences between the Polish, Slovak and Czech nurses in the study, regarding psychological burden and occupational burnout, and the differences between these parameters divided into subscales were examined. Monofactorial analysis of variance to nurses from Poland and Slovakia. For the non-specific factor scale, there are differences between the group from Slovakia and the group from the Czech Republic. The highest result was obtained by the group from Slovakia. 
In the case of the sense of personal achievement subscale, nurses from Poland differ from the other two groups, while there are no differences between the Slovakian group and the group from the Czech Republic. The Polish participants achieved significantly lower results compared to the other groups. In terms of depersonalization, the only statistically significant difference is between the group of Polish nurses and the Czech group, which has a higher score on this scale. The measure of effect size, $\eta^{2}$, indicates that the strongest differences relate to overload, the other differences are similar to each other, but have a lower strength than overload.

\section{Discussion}

One of the important elements of workload is psychological burden, defined as a subjective reaction of the employee, which is a result of the interaction of a set of individual, technical, organizational and social factors in the work environment (8). The research task is broadly related to the management of health and safety at nurses' workplaces, which is undertaken by the Inter-national Council of Nurses, as well as the International Labor Organization (ILO). These organizations encourage the use of international projects to ensure the nurse's right to a safe working environment that considers emotional and psychosocial burdens (9).

Table 4: Differences of occupational burnout and psychological burden of the groups studied

\begin{tabular}{|c|c|c|c|c|c|c|c|c|c|}
\hline & \multicolumn{2}{|l|}{ Poland } & \multicolumn{2}{|c|}{ Slovakia } & \multicolumn{2}{|c|}{ Czech Republic } & \multirow{2}{*}{$F$} & \multirow{2}{*}{$p$} & \multirow{2}{*}{$\eta^{2}$} \\
\hline & $M$ & $S D$ & $M$ & $S D$ & $M$ & $S D$ & & & \\
\hline overload & $9.30_{b}$ & 2.07 & $8.78_{b}$ & 2.32 & $7.61_{a}$ & 1.91 & 17.43 & $<0.001$ & 0.10 \\
\hline monotony & $5.52_{\mathrm{a}}$ & 1.76 & 5.41 & 1.72 & $5.01_{b}$ & 1.64 & 2.57 & 0.078 & 0.02 \\
\hline non-specific factor & 10.20 & 3.18 & $11.00_{\mathrm{a}}$ & 3.20 & $9.62_{b}$ & 3.17 & 4.78 & 0.009 & 0.03 \\
\hline $\begin{array}{l}\text { emotional } \\
\text { exhaustion }\end{array}$ & 18.69 & 8.93 & 21.79 & 11.72 & 19.13 & 11.25 & 2.55 & 0.079 & 0.02 \\
\hline $\begin{array}{l}\text { sense of personal } \\
\text { achievement }\end{array}$ & $25.16_{a}$ & 6.47 & $27.84_{b}$ & 6.53 & $28.04_{b}$ & 6.92 & 5.96 & 0.003 & 0.04 \\
\hline depersonalization & 6.09 & 5.05 & 7.55 & 7.19 & $9.01_{b}$ & 5.71 & 5.96 & 0.003 & 0.04 \\
\hline
\end{tabular}

Note: The averages with different letter indexes differ from each other at the level of $p<0.05$. NIR and Games-Howell Test. The Levene Test showed that the assumption about the homogeneity of the variance of the groups compared breaks down in the case of emotional exhaustion, depersonalization and general burnout. For that reason, Games-Howell Post Hoc Tests were carried out on these variables, while on remaining ones, NIR Tests were carried out. 
In the literature, this problem is becoming a new challenge for ergonomics and is the reason for studying these groups of nurses $(10,11,12,13)$. In Poland, Slovakia and the Czech Republic the issue of occupational burnout and psychological burden in the work of nurses is marginalized and requires thorough diagnosis.

Burnout syndrome does not arise suddenly but is the result of a gradual process. Analysis of the literature shows that during this process various dimensions of burnout develop sequentially. In the first stage, the process is triggered by highly demanding environments. Then, in order to cope with those demands, people increasingly distance themselves from their work and other people. That is to say, they develop a defense strategy that manifests itself through depersonalization. In the end, the person's ability to work effectively diminishes. In this model, emotional exhaustion acts as a factor influencing depersonalization and reduced ability to work (14).

As part of our research, we focused on the analysis of factors influencing psychological burden and burnout of nurses working in Intensive Care Units. We have assumed that in the assessment of working conditions, it is important to make international comparisons, which is possible because we now have one common research tool, the standardized Meister Questionnaire in its Czech, Slovak and Polish versions $(3,4,5,6)$. Different results were observed between the groups studied depending on the age and length of service of the nurses in the Intensive Care Units. The greatest differences concerned overload, non-specific stress response, feelings of personal achievement and depersonalization. This points to a different level of risk of occupational burnout and psychological burden. A significant trend was observed indicating that age has an influence on sense of personal achievement and depersonalization. The older the group, the less depersonalization, psychological burden and sense of achievement, which leads to reduced satisfaction and productivity at work. The oldest group of Polish nurses, in contrast to Slovak and Czech nurses, did not experience psychological burden. A clear sense of lack of personal satisfaction with work appeared in this group, but the level of depersonalization was relatively low, which is a positive phenomenon. The Czech nurses were the youngest of all those studied, and no relationship was found between burnout and psychological burden in this group. In the case of the Czech nurses, in relation to their length of service in Intensive Care units, we noted a substantially higher level of depersonalization. The Slovak nurses, relative to the Polish and Czech nurses, were characterized by a higher level of non-specific factor (reaction to stress). Amongst the Polish nurses, length of service in the unit was related significantly to monotony. This is evidence that the work of nurses in Intensive Care Units is demanding and diverse, and that this can bring job satisfaction and thus reduce the risk of burnout. However, length of service in the same workplace is a risk factor for occupational burnout. The least overloaded nurses were those with shorter length of service.

These results agree with the work of Pilárika et al. (15) and Włodarczyk et al. (16). They showed the following predictors of burnout: a lack of ability to regulate emotion; personality types associated with a strong need for achievement and with a tendency to domination and aggression; as well as personality traits such as dynamism, energy, impatience and a tendency to act quickly. This confirms the thesis that nurses with increased ability to regulate their emotions showed a lower level of depersonalization, which perhaps typifies the 
younger group of nurses from the Czech Republic. Pauknerová et al. (17) point out that, although workers become more knowledgeable with age and experience, their productivity at work decreases; are less likely to search for new solutions; are slower to meet rapidly growing expectations. Therefore, older employees prove themselves in less demanding tasks. This is due to lower concentration; less ability to adapt to information overload and stress; to learn new things. Also, in the work of Asai et al. (18) it has been demonstrated that a higher level of depersonalization, a feeling of lack of achievement, and greater emotional exhaustion was more frequently observed among younger nurses (under 27 years of age) than among older nurses.

However, Z. Žídková (4) in her study showed that in groups of medical workers overload was highest in nurses and doctors, while the non-specific factor (reaction to stress) was highest in the group of theatre scrub nurses. In other Czech research, A. Mažgútová et al. (19) have shown that psychological burden in the work of nurses is highest in the palliative care ward compared to the medical or emergency ward. However, in Polish studies, no clear results were obtained. In one of these, the level of psychological burden did not differ between a group of oncology nurses and those working in other specialties (12). In another study, it was shown that nurses working in an intensive medical care unit have a significantly lower level of burden than those in the surgical ward (14).

In this context, Hodáčová et al. (20) state that psychological stress is a complex phenomenon, caused by various psychosocial factors, directly related to the work performed, as well as personality factors, and should be considered individually in each profession and in each position.

\section{Conclusions}

Considering the main objective of this study it has been shown that nurses working in intensive care in Poland, Slovakia and the Czech Republic are exposed to psychological stress and occupational burnout syndrome. Our results support the conclusions of previous studies that there is a relationship between age and time worked at one workplace, and stress and burnout. Bearing in mind the health risks caused by the workload of nurses, preventive measures should be taken regardless of the country of origin and place of work. Within these measures, it is worth supporting and developing positive self-esteem and strategies for dealing with stress. The results of the research can be used to improve the organization of nursing work and create safe working conditions, bearing in mind the mobility of employees in EU countries.

\section{References}

1. GLOWACKA M, ORZOL A, SOLETA A (2012) Adverse events in the practice of critical care and anesthesiological nurses. Journal of Public Health, Nursing and Medical Rescue 2012; 4:5-13. ISSN: 2299-9140.

2. KOWALCZUK K, ZDANSKA A, KRAJEWSKA-KULAK E, et al (2011) Stress in the work of Nurses as a risk factor for burnout. In Problemy Pielęgniarstwa 19 (Mar), p 307-314. ISSN:1233-9989.

3. MINISTER OF HEALTH REGULATION OF AUGUST 16, 2007 Rules of health protection against physical, mental and sensory load at work. n. 542, 3896.

4. ZIDKOVA Z (2002) The application of Questionnaire in the evaluation of psychic load at work In Czech Labor Medicine, Mar. p 128-132.

5. HLADKY A, ZIDKOVA Z (1999) Methods for assessing occupational psychosocial load. Karolinum Praga, p 78. 
6. DEBSKA G, WILCZEK-RUZYCZKA E, FORYS Z, PASEK M (2013) Psychometric properties assessment of the Meister Questionnaire used in evaluating mental load among Nurses. In Medycyna Pracy 64(MAR) 349-358. ISSN:0465-5893.

7. PASIKOWSKI T (2009) Polish adaptation of the Maslach Burnout Inventory Questionnaire. In: Sęk H. (eds) Occupational burnout. Causes and prevention. In Wydawnictwo Naukowe PWN Warszawa, p 135-149.

8. LUCZAK A (2011) Standardization work regarding mental workload. In: Juliszewski T, Ogińska H, Złowodzki M. (eds) Mental workload - new challenges for ergonomics. In Ergonomii PAN - Kraków p 105-115.

9. PAPP E, M (2007) Occupational Health and Safety Management Programme for Nurses. Copyright by International Council of Nurses (ICN).

10. ZALESAKOVA J, BUZGOVA R (2011) Psychological stress of Nurses taking care of cancer patients. In Labor Medicine, 6 (34): 113-118. ISSN:0032-6296.

11. GURKOVA E, SLAVKA M (2012) Psychological strain and depressive symptomatology between Nurses. In Nursing and midwifery, 3(Jan) 326-334. ISSN: 1804-2740.

12. DEBSKA G, PASEK M, WILCZEK-RUZYCZKA E (2014) Psychological strain and occupational burnout among nurses of various specialties. Hygeia Public Health 2014, 49(Jan): 113-119. ISSN:1509-1945.

13. DEBSKA G, PASEK M, WILCZEK-RUŻYCZKA E, FORYS Z (2013) Psychological burden experienced by Nurses in oncology units vs. Nurses employed in other medical units. In. Moravcikova D, Vasko M (eds)
(2013) Family-Health-Disease 2013: p 109119. Tomas Bata University Zlĭn in Czech Republic. ISBN 978-80-7454-411-8.

14. TANNER S,T (2011) Process of Burnout Structure, Antecedents, and Consequences. Tampere: Juvenes Print, p 109.

15. PILARIK L, TOBAKOSOVAZ(2013)Emotional intelligence and burn-out syndrome of nurses. In Ořetrovatel'stvo:teória,výskum, 3(1); 5-10. ISSN 1338-6263

16. WLODARCZYK D, PAWLISZEWSKA A (2015) Type a behavior as a predictor of burnout and job satisfaction in intensive care units nurses. In: Medycyna Pracy, 2015, 66(2): 213-224. ISSN:0465-5893

17. PAUKNEROVA D (2006) Psychology for Economists and Managers. Praha: Grada Publishing p 256.

18. ASAI M, MORITA T, AKECHI T (2007) Burnout and psychiatric morbidity among physicians engaged in end-of-life care for cancer patients: A cross-sectional nationwide survey in Japan. In: Psycho-Oncology, 2007, 16: 421-428. ISSN:1099-1611.

19. MAZGUTOVA A, ONDREJKA I, DEMETEROVA M, FETISOVOVA Z, ADAMICOVA K (2012) The psychological burden of health care workers in palliative care. In Palliative medicine and pain management, 5 (Mar): 95-98. ISSN:1339-419.

20. HODACOVA L, SMEJKALOVA J, SKALSKA H (2007) Differences in occupational psychic load perception among workers of chosen professional groups. In Medical reports from the Medical Faculty of the Charles University in Hradec. 52 (Feb) 93103. ISSN: 0457-4206. 